\title{
GENOTYPIC CONTROL OF CHROMOSOME BEHAVIOUR IN RYE. II. DISJUNCTION AT MEIOSIS IN INTERCHANGE HETEROZYGOTES
}

\author{
J. BRYAN THOMPSON \\ Agricultural Research Council Unit of Biometrical Genetics, \\ Department of Genetics, University of Birmingham
}

Received 24.vi.55

\section{INTRODUCTION}

IN interchange heterozygotes the rings and chains of four chromosomes seen at first meiotic metaphase fall into two classes, arranged disjunctionally and non-disjunctionally. Disjunctional arrangements appear as zig-zag configurations with successive centromeres directed to opposite poles thus,

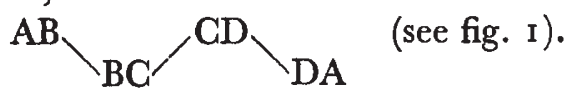

This arrangement results in balanced viable gametes. Non-disjunctional arrangements do not show this alternation of centromere orientation, and appear as open ring or chain configurations : e.g.

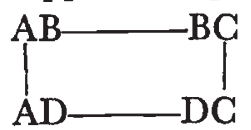

or

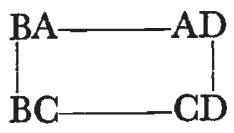

In plants these configurations result in the production of inviable gametes.

Interchange heterozygotes in Pisum (Pellew and Sansome, I93I) and in maize (Burnham, r934) give disjunctional and non-disjunctional arrangements with approximately equal frequencies and, as would then be expected, these plants show about $5^{\circ}$ per cent. pollen and ovule sterility. In other species, however, plants heterozygous for an interchange show less than 50 per cent. sterility; e.g. Campanula (Darlington, 1937) shows only $3^{\circ}$ per cent. sterility, disjunction occurring in about 70 per cent. of cases. The higher disjunction of Campanula is accounted for by its larger chromosomes and by the high degree of terminalisation of its chiasmata (Darlington l.c.).

Genotypic control of disjunction may be inferred from the differences between species, but hitherto it has been analysed no further. The present account is concerned with differences in the disjunction properties of interchange configurations within a single species, differences which therefore afford an opportunity of further investigation by breeding experiments.

\section{MATERIAL AND METHOD}

In $195^{1}$ an $F_{1}$ plant from a cross between two inbred lines of rye was found to be heterozygous for two independent interchanges. 
These two interchange configurations were distinguishable at diplotene (fig. I) as :

Interchange $A$, involving the nucleolar organiser chromosome, and Interchange $B$, involving unequal lengths of chromosome, so that the ring or chain of four consisted of one short, one long, and two chromosomes of normal length.

The subsequent history of the plants used is shown in fig. 2. In
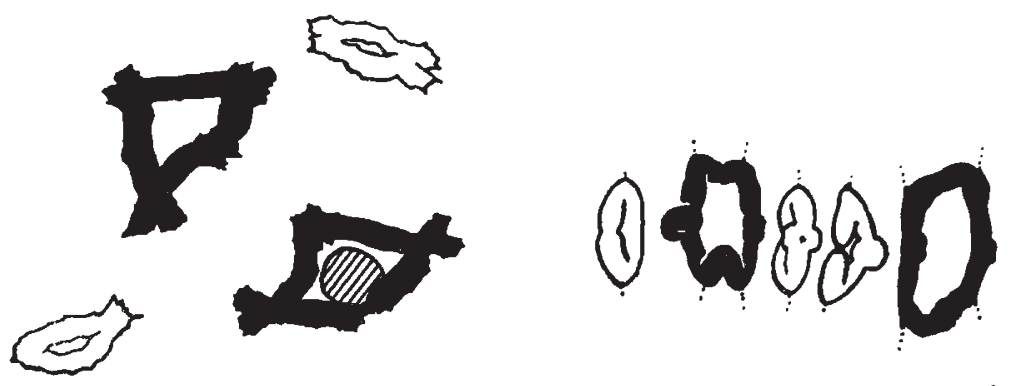

b

a
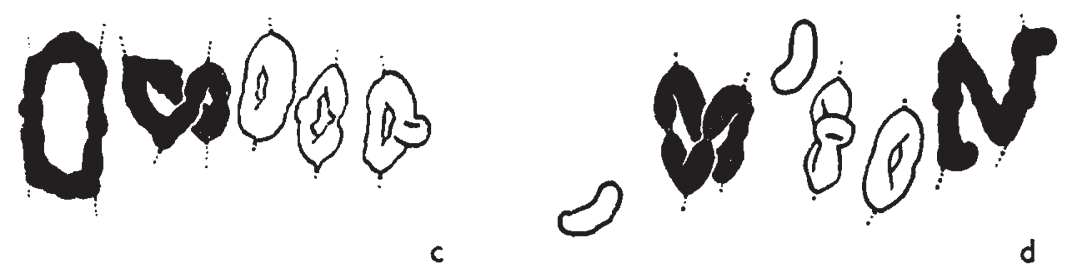

$c$

d

Fic. 1.-Meiosis in plants heterozygous for both of the interchanges.

(a) Diplotene

(b) M I showing two non-disjunctional rings of 4

(c) M I showing non-disjunctional and disjunctional rings of 4

(d) M I showing disjunctional ring and chain of 4 . Two chromosomes are unpaired.

$\times 1080$.

each generation seed was obtained by self pollination of plants heterozygous for both interchanges, each family being the progeny of a single plant.

The $F_{1}$ plant was heterozygous for both interchanges. In subsequent generations, as a result of segregation, some plants were structural homozygotes, some were heterozygous for one of the interchanges, and some were heterozygous for both.

The interchange heterozygotes were classified into types A, B and $\mathrm{AB}$ at diplotene, and the number of disjunctional and nondisjunctional arrangements were then scored in 20 first metaphase cells of each of these plants. 


\section{RESULTS AND ANALYSES \\ $F_{3}$}

The observed numbers of disjunctional and non-disjunctional arrangements in each $\mathrm{F}_{3}$ family are set out in table $\mathrm{I}$.

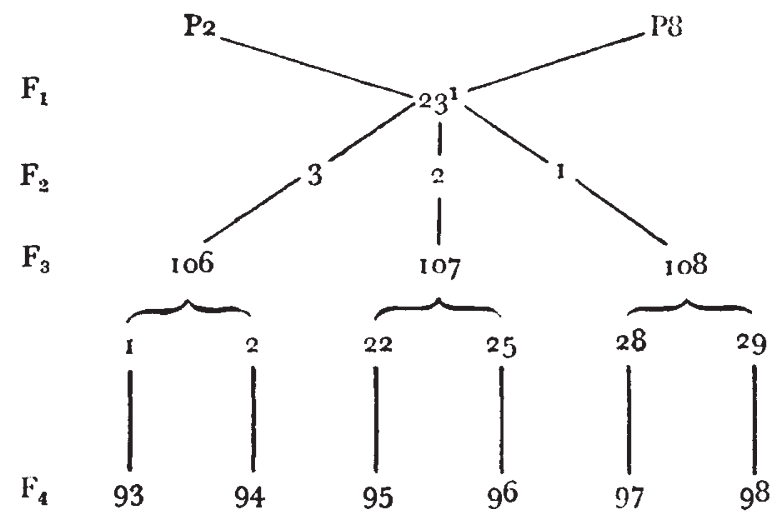

Fig. 2.- The history of the material. $\mathrm{P}_{2}$ and $\mathrm{P} 8$ are inbred lines. Each number represents a family in $F_{2}, F_{3}$ and $F_{4}$ which in turn represents the progeny of a single plant self-pollinated in the previous generation.

To test whether all of the $F_{3}$ families are behaving alike we can find estimates of the disjunction frequency, and compare these estimates with the observed values in a $\chi^{2}$ analysis.

TABLE

The observed numbers of disjunctional $(D)$ and non-disjunctional $(\mathcal{N})$ arrangements in the $F_{3}$ families. (Each entry is the total from 20 cells scored in each plant)

\begin{tabular}{|c|c|c|c|c|c|c|c|c|c|c|}
\hline Interchange & \multicolumn{3}{|c|}{$\mathbf{A}$} & \multicolumn{4}{|c|}{$A$ and $B$} & \multicolumn{3}{|c|}{ B } \\
\hline Class & $\begin{array}{l}\mathrm{D} \\
a_{1}\end{array}$ & $\begin{array}{l}\mathrm{N} \\
a_{2}\end{array}$ & $\begin{array}{l}\text { No. of } \\
\text { plants }\end{array}$ & $\begin{array}{l}\mathrm{DD} \\
a_{3}\end{array}$ & $\begin{array}{c}\mathrm{DN} \\
a_{4}\end{array}$ & $\begin{array}{l}\mathrm{NN} \\
a_{5}\end{array}$ & $\begin{array}{l}\text { No. of } \\
\text { plants }\end{array}$ & $\begin{array}{l}\mathrm{D} \\
a_{8}\end{array}$ & $\begin{array}{l}\mathrm{N} \\
a_{7}\end{array}$ & $\begin{array}{l}\text { No. of } \\
\text { plants }\end{array}$ \\
\hline $\begin{array}{l}\text { I } 06 \\
107 \\
\text { I } 08\end{array}$ & $\begin{array}{r}18 \\
102 \\
89\end{array}$ & $\begin{array}{l}\text { I } 4 \\
3 \mathrm{I} \\
3 \mathrm{I}\end{array}$ & $\begin{array}{l}2 \\
8 \\
6\end{array}$ & $\begin{array}{l}\text { I } 6 \\
30 \\
5^{8}\end{array}$ & $\begin{array}{l}24 \\
23 \\
34\end{array}$ & $\begin{array}{r}\text { I } 4 \\
9 \\
5\end{array}$ & $\begin{array}{l}4 \\
4 \\
5\end{array}$ & $\begin{array}{r}5 \\
63 \\
49\end{array}$ & $\begin{array}{r}7 \\
27 \\
10\end{array}$ & $\begin{array}{l}I \\
5 \\
3\end{array}$ \\
\hline $\begin{array}{c}\text { Total } \\
\text { Proportion }\end{array}$ & $\begin{array}{l}209 \\
p_{a}\end{array}$ & $\begin{array}{l}76 \\
q a\end{array}$ & $\begin{array}{l}{ }^{\prime} 6 \\
\ldots\end{array}$ & $\begin{array}{l}104 \\
p_{a} p_{b}\end{array}$ & $\begin{array}{c}8 \mathrm{I} \\
p_{a} q_{b} \\
+ \\
q_{a} p_{b}\end{array}$ & $\begin{array}{c}28 \\
q_{a} q_{b}\end{array}$ & $\begin{array}{l}13 \\
\ldots\end{array}$ & $\begin{array}{l}\text { II } 7 \\
p_{b}\end{array}$ & $\begin{array}{l}44 \\
q_{b}\end{array}$ & $\begin{array}{l}9 \\
\cdots\end{array}$ \\
\hline
\end{tabular}

The most efficient method of finding the estimates is by maximum likelihood. If $p_{a}$ equals the disjunction frequency of interchange $\mathrm{A}$, $q_{a}\left(=\mathrm{I}-p_{a}\right)$ the frequency of non-disjunction, and $p_{b}$ and $q_{b}$ the frequencies for interchange $B$, then the frequencies of the seven classes in table $\mathrm{I}$ are as shown in the last row of the table. 
The log likelihood expression is

$$
\begin{aligned}
\mathrm{L}= & a_{1} \log p_{a}+a_{2} \log q_{a}+a_{3} \log p_{a} p_{b}+a_{4} \log \left(p_{a} q_{b}+q_{a} p_{b}\right) \\
& +a_{5} \log q_{a} q_{b}+a_{6} \log p_{b}+a_{7} \log q_{b} \\
=\left(a_{1}+a_{3}\right) \log p_{a}+\left(a_{2}+a_{5}\right) \log q_{a}+a_{4} \log \left(p_{a} q_{b}+q_{a} p_{b}\right) & +\left(a_{3}+a_{6}\right) \log p_{b}+\left(a_{5}+a_{7}\right) \log q_{b} \\
&
\end{aligned}
$$

Partial differentiation with respect to $p_{a}$ and $p_{b}$ gives the maximum likelihood equations

$$
\begin{aligned}
& \frac{d \mathrm{~L}}{d p_{a}}=\frac{a_{1}+a_{3}}{p_{a}}-\frac{a_{2}+a_{5}}{q_{a}}+\frac{a_{4}\left(q_{b}-p_{b}\right)}{p_{a} q_{b}+q_{a} p_{b}}=0 \\
& \frac{d \mathrm{~L}}{d p_{b}}=\frac{a_{3}+a_{6}}{p_{b}}-\frac{a_{5}+a_{7}}{q_{b}}+\frac{a_{4}\left(q_{a}-p_{a}\right)}{p_{a} q_{b}+q_{a} p_{b}}=0
\end{aligned}
$$

which reduce to

$$
\begin{gathered}
2\left(a_{1}+a_{2}+a_{3}+a_{4}+a_{5}\right)^{2} \quad p_{a}^{3} \\
-\left(a_{1}+a_{2}+a_{3}+a_{4}+a_{5}\right)\left(5 a_{1}+a_{2}+6 a_{3}+3 a_{4}+a_{6}-a_{7}\right) p_{a}^{2} \\
+\left\{\left(a_{1}+a_{3}+a_{4}\right)\left(4 a_{1}+a_{2}+5 a_{3}+a_{4}+a_{6}-a_{7}\right)+\left(a_{1}+a_{3}\right)\left(a_{2}+a_{5}\right)\right. \\
\left.+\left(a_{3}+a_{6}\right)\left(a_{1}+a_{2}+a_{3}+a_{5}\right)\right\} p_{a} \\
-\left(a_{1}+a_{3}\right)\left(a_{1}+2 a_{3}+a_{4}+a_{6}\right)=0
\end{gathered}
$$

and

$$
p_{b}=\frac{\left\{\left(a_{1}+a_{2}+a_{3}+a_{4}+a_{5}\right) p_{a}-\left(a_{1}+a_{3}+a_{4}\right)\right\} p_{a}}{2\left(a_{1}+a_{2}+a_{3}+a_{4}+a_{5}\right) p_{a}^{2}-\left(3 a_{1}+a_{2}+3 a_{3}+2 a_{4}+a_{5}\right) p_{a}+a_{1}+a_{3}}
$$

TABLE 2

The maximum. likelihood estimates of the disjunction and non-disjunction frequencies in the $F_{3}$

\begin{tabular}{|c|c|c|c|c|}
\hline Family & $p_{a}$ & $q_{a}$ & $p_{b}$ & $q_{b}$ \\
\hline 106 & 0.5616 & 0.4384 & 0.4650 & 0.5350 \\
107 & 0.7461 & 0.2539 & 0.6744 & 0.3256 \\
108 & 0.7367 & 0.2633 & 0.8213 & 0.1787 \\
$\begin{array}{c}\text { Estimate over } \\
\text { all families }\end{array}$ & 0.7136 & 0.2864 & 0.6944 & 0.3056 \\
\hline
\end{tabular}

The equation for $p_{a}$ can be solved by iteration, and that for $p_{b}$ by substitution of the value of $p_{a}$. The estimates from the $F_{3}$ families, separately and pooled, are set out in table 2 .

The estimates of $p_{a}$ and $p_{b}$ derived from the $F_{3}$ totals are used to obtain expectations for the various classes in each of the three families. We can then calculate a $\chi^{2}$ testing the goodness of fit of the frequencies observed with the overall estimate of disjunction. This $\chi^{2}$ has ten degrees of freedom (see appendix) and will, of course, be influenced by any differences that may exist between the $F_{3}$ families, as well as by variation within them.

Using the estimate obtained from each individual family a $\chi^{2}$ for two degrees of freedom can be found testing the goodness of fit within each of the three families. The total of these three $\chi^{2}$ is itself 
a $\chi^{2}$ for six degrees of freedom, and it will test whether departures from expectation within families are small enough to be attributed to sampling error. If significantly large it will reveal interaction between the interchanges within the family, i.e. whether one interchange affects the disjunction of the other in plants heterozygous for both of them.

The difference between the $\chi^{2}{ }_{10}$ and the $\chi^{2}{ }_{6}$ is a $\chi^{2}$ for four degrees of freedom which tests for heterogeneity of $p$ values between the three families.

The analysis of the $F_{3}$ is set out below.

\begin{tabular}{|c|c|c|c|c|}
\hline Item & & $\chi^{2}$ & $\mathbf{N}$ & $\mathbf{P}$ \\
\hline Heterogeneity between families & . & $40 \cdot 4118$ & 4 & $<0.001$ \\
\hline Interaction within families & • & $4 \cdot 8332$ & 6 & $0.50-0.70$ \\
\hline Total . & . & $45 \cdot 245^{\circ}$ & xo & \\
\hline
\end{tabular}

It will be seen from this analysis that :

I. There is no significant interaction effect within families.

2. The families are highly heterogeneous : they show different frequencies of disjunction.

The significant heterogeneity of $\mathrm{F}_{3}$ families strongly suggests segregation at meiosis in the $F_{1}$ for genes controlling the disjunction of the interchanges.

$\mathrm{F}_{4}$

As a further test of the hypothesis that the $F_{3}$ heterogeneity can be explained in terms of a genetic segregation six $\mathrm{F}_{4}$ families were grown and analysed. These six families were grouped into three pairs according to their ancestry (see fig. 2). The observed numbers of disjunctional and non-disjunctional arrangements in the $F_{4}$ families are given in table 3 . Table 4 shows the values of $p_{a}$ and $p_{b}$ estimated from these observations.

The analysis of the $\mathrm{F}_{4}$ is made in the following way :-

(I) The overall estimates are used in each of the six families to obtain a total $\chi^{2}$ for twenty degrees of freedom (see appendix). This $\chi^{2}$ tests overall goodness of fit.

(2) Using the estimates from the paired family totals and calculating expectations for each of the two families making up the pair, two $\chi^{2}$ for six degrees of freedom (families 93 and 94, and 95 and 96 ) and one $\chi^{2}$ for four degrees of freedom (families 97 and 98) can be obtained. These $\chi^{2}$ test for variation between the members of a pair of families and within the families. Together these three $\chi^{2}$ make up a $\chi^{2}$ for sixteen degrees of freedom. 
(3) The estimates of $p_{a}$ and $p_{b}$ obtained from each individual family are used to obtain the interaction $\chi^{2}$ as in the analysis

TABLE 3

Numbers of disjunctional and non-disjunctional arrangements in the $F_{4}$ families (2o cells in each plant)

\begin{tabular}{|c|c|c|c|c|r|r|r|r|r|r|}
\hline \multirow{2}{*}{ Family } & \multicolumn{3}{|c|}{ A } \\
\cline { 2 - 11 }
\end{tabular}

TABLE 4

The maximum likelihood values of $\mathrm{p}_{a}$ and $\mathrm{p}_{b}$ estimated from each row of table 3

\begin{tabular}{|c|c|c|}
\hline Family & $p_{a}$ & $p_{b}$ \\
\hline & 0.6986 & 0.7716 \\
93 & 0.6478 & 0.7140 \\
94 & 0.8303 & 0.8401 \\
95 & 0.8009 & 0.7325 \\
96 & 0.7863 & 0.8845 \\
97 & 0.8210 & 0.8505 \\
98 & 0.6746 & 0.7604 \\
93 and 94 & 0.8236 & 0.7947 \\
95 and 96 & 0.8019 & 0.8737 \\
97 and 98 & 0.7654 & 0.7852 \\
\hline
\end{tabular}

of the $\mathrm{F}_{3}$. Four of these $\chi^{2}$ items have two degrees of freedom (families 93, 94, 95 and 96) and two of them have one degree of freedom (families 97 and 98). The total of these items is therefore a $\chi^{2}$ for ten degrees of freedom testing for interaction between the interchanges in double heterozygotes. 
(4) The difference between ( 1 ) and (2) above is a $\chi^{2}$ for four degrees of freedom testing for heterogeneity of $p$ values between the three family pairs (analogous to heterogeneity between the three $\mathrm{F}_{3}$ families).

(5) The difference between (2) and (3) above is a $\chi^{2}$ for six degrees of freedom testing for heterogeneity between members of the same family pair. (A test of genetic heterogeneity within the $\mathrm{F}_{3}$ families, i.e. of segregation at meiosis in the $F_{2}$ plants.)

The results of this analysis are set out below.

\begin{tabular}{|c|c|c|c|}
\hline Item & $\chi^{2}$ & $\mathrm{~N}$ & $\mathbf{P}$ \\
\hline $\begin{array}{l}\text { I Grand total } \\
2 \text { Family pairs total }\end{array}$ & $\begin{array}{l}61 \cdot 0249 \\
26 \cdot 1213\end{array}$ & $\begin{array}{l}20 \\
16\end{array}$ & $\cdots$ \\
\hline $\begin{array}{l}\text { I-2 Heterogeneity between family } \\
\text { pairs }\end{array}$ & $34.903^{6}$ & 4 & $<0.00 r$ \\
\hline $\begin{array}{l}3 \text { Interaction within families } \\
2-3 \text { Heterogeneity within family pairs }\end{array}$ & $\begin{array}{r}\text { I } 8 \cdot 6678 \\
7 \cdot 4535\end{array}$ & $\begin{array}{r}10 \\
6\end{array}$ & $\begin{array}{l}0.05-0 \cdot 02 \\
0 \cdot 3-0 \cdot 2\end{array}$ \\
\hline
\end{tabular}

It can be seen that :-

(I) There is heterogeneity between the three pairs of families. This heterogeneity confirms that observed at $\mathrm{F}_{3}$.

(2) There is no sign of heterogeneity between the families within pairs.

(3) There is some doubt as to the presence of interaction within families. When the individual family $\chi^{2}$ are examined (see table 5) it can be seen that families 93 and 94 make up nearly the whole of the interaction item.

TABLE 5

The interaction $\chi^{2}$ of the $F_{4}$ families

\begin{tabular}{|c|c|c|c|}
\hline Family & $\chi^{2}$ & $\mathrm{~N}$ & $\mathbf{P}$ \\
\hline $\begin{array}{l}93 \\
94 \\
95 \\
96 \\
97 \\
98\end{array}$ & $\begin{array}{l}4 \cdot 8735 \\
7 \cdot 1178 \\
1 \cdot 9865 \\
1 \cdot 7616 \\
2 \cdot 7136 \\
0 \cdot 2148\end{array}$ & $\begin{array}{l}2 \\
2 \\
2 \\
2 \\
1 \\
1\end{array}$ & $\begin{array}{c}o \cdot r-0.05 \\
0.05-0.02 \\
\ldots \\
\ldots \\
\ldots \\
\ldots\end{array}$ \\
\hline
\end{tabular}

There is no evidence of interaction within families 95, 96, 97 and 98 but we cannot neglect the possibility of interaction in families 93 and 94. Further evidence must be sought in future years.

That the difference between $F_{3}$ families is a result of segregation of genes controlling disjunction is confirmed by the variation between 
family pairs in the $F_{4}$. Fig. 3 shows that the disjunction values of parents $\left(F_{3}\right)$ and offspring $\left(F_{4}\right)$ are closely correlated. It is clear, therefore, that the frequency of chromosome disjunction as opposed to non-disjunction is subject to genotypic control.

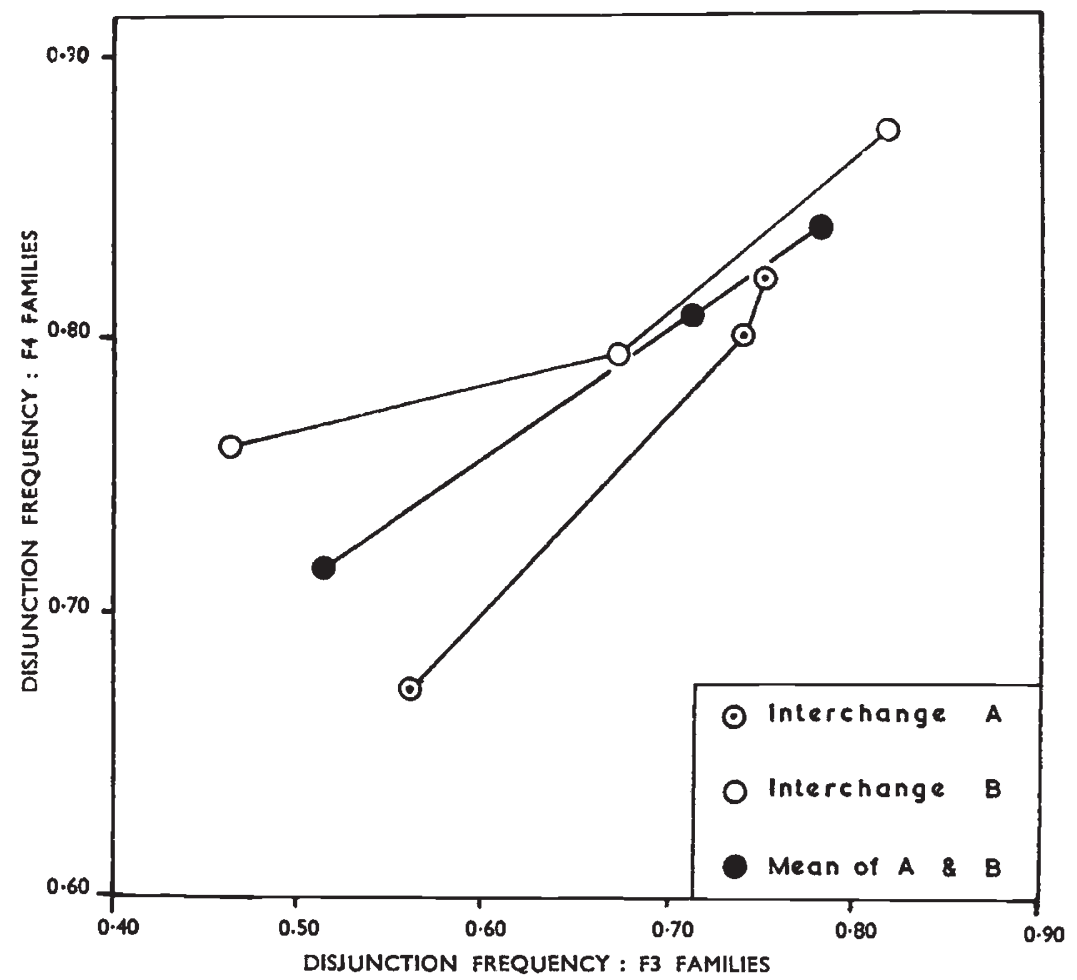

Fig. 3.-Graph showing correlation of disjunction frequencies between the three $F_{3}$ families and their $\mathrm{F}_{4}$ offspring. Data taken from tables 2 and 4 , the figures used in the $F_{4}$ being the estimates from the pooled pairs of families.

\section{DISCUSSION}

The above account shows that variation in disjunction frequency of the same chromosome interchanges in rye is due in part to variation in the genotype. Heritable variation in disjunction within a species may well also account for the variation in pollen and ovule sterility reported by Burnham (1934) in maize "cultures" heterozygous for interchange T8-9.

There is evidence suggesting that disjunction in the permanent interchange hybrids of Oenothera is genotypically controlled. The species have been shown to have characteristic disjunction frequencies. Cleland (1926), for example, reports that just over 20 per cent. of metaphases in $O$. muricata show deviation from complete disjunction, while in $O$. pratinicola (Kulkarni, 1929) only 3 to 7 per cent. of metaphases show such deviations.

Heritable variation in chromosome behaviour is subject to the 
action of natural selection in just the same way as the more conventional morphological characters (see Rees, 1955). In interchange heterozygotes natural selection would clearly favour those genotypes which lead to a high proportion of disjunctional arrangements and to a relatively high fertility. Such selection may well have played an important part in populations of two kinds, firstly, where interchanges float in the population, some individuals being homozygotes and some heterozygotes (e.g. Campanula, Darlington and Gairdner, 1937), and secondly, where the interchanges are fixed in the heterozygous condition as in Oenothera and Rhoeo. In both these types of population the heterotic advantages of structural heterozygosity are counterbalanced by a loss of fertility. Selection may well have minimised this infertility by adjustment of the degree of disjunction at meiosis.

\section{SUMMARY}

I. The frequency of genetical disjunction of interchange configurations in rye is shown to be genotypically controlled.

2. There is some evidence that in plants of some families the disjunction properties of two interchange configurations are not independent.

3. Since the disjunctional properties of interchange heterozygotes are heritable, selection would be effective in adjusting the degree of disjunction to achieve greater fertility. Such selection may well have played an important part in the establishment of interchange heterozygotes in populations of species in Oenothera and Campanula.

\section{APPENDIX}

The data from each family in $\mathrm{F}_{3}$ and $\mathrm{F}_{4}$ is a combination of three groups. Two of the groups stem from the plants heterozygous for the A and the B interchanges respectively, and each of these provides two classes of observation, viz. disjunction and non-disjunction of the interchange in question. Thus each provides one degree of freedom for testing agreement with any expected frequency of disjunction. The third group, consisting of the double heterozygous individuals, provides three classes of observation, viz. disjunctional for both, for only one, and for neither of the interchanges. This third group gives us two degrees of freedom.

There are thus four degrees of freedom appropriate to each row of tables $I$ and 3 . By using the values of $p_{a}$ and $p_{b}$ estimated from any one row and finding expected values for that row, we get a $\chi^{2}$ for two degrees of freedom, the other two having been used in estimating $p_{a}$ and $p_{b}$. Similarly, by using estimates derived from the $\mathrm{F}_{3}$ totals and finding expectations for the three $\mathrm{F}_{3}$ families we get a $\chi^{2}$ for $3 \times 4$ degrees of freedom, less the two degrees of freedom used in estimating the parameters, i.e. a $\chi^{2}$ for ten degrees of freedom.

Since there are no observations on plants heterozygous for interchange B in families 97 and 98 of the $F_{4}$, the number of degrees of freedom appropriate to these two families is $(2+1)-2=1$.

Acknowledgments.-I am indebted to Professor K. Mather, F.R.s., Dr H. Rees and Dr B. I. Hayman for their advice. The resolution of the maximum likelihood equations to their cubic form is due to Dr Hayman. 


\section{REFERENCES}

Burnham, G. R. 1934. Cytogenetic studies of an interchange between chromosomes 8 and 9 in maize. Genetics, 19, 430-447.

CLeland, R. E. 1926. Cytological studies of meiosis in anthers of Oenothera muricata. Bot. Gaz., 82, 55-70.

DARlington, C. D. 1937. Recent Advances in Cytology. 2nd ed. London : J. and A. Churchill.

DARLINGTON, C. D., AND GAIRDNER, A. E. 1937. The variation system in Campanula persicifolia. Journ. Gen., 35, 97-128.

KULKARNI, C. 1929. Meiosis in pollen mother cells of strains of Oenothera pratinicola Bartlett. Bot. Gaz., 87, 2 18-259.

PEllew, C., AND SANSOMe, E. R. I931. Genetical and cytological studies on the relations between Asiatic and European varieties of Pisum sativum. Fourn. Gen., $25,24-54$.

REES, H. 1955. Genotypic control of chromosome behaviour in rye. I. The inbred lines. Heredity, 9, 93-г 16. 